\title{
Xanthopsia and van Gogh's Yellow Palette
}

\author{
WILFRED NIELS ARNOLD ${ }^{1}$ and LORETTA S. LOFTUS ${ }^{2}$ \\ Kansas City, USA
}

\begin{abstract}
Summary
A survey of van Gogh's work from 1886 to 1890 indicated that paintings with a yellow dominance were numerous, episodic, and multi-regional. His underlying illness, by his own admission, affected his life and work; furthermore, episodes of malnutrition, substance abuse, environmental exposure, and drug experimentation (all evident from correspondence) exacerbated his condition. Accordingly, we reviewed plausible agents that might have modified the artist's colour perception. Xanthopsia due to overdosage of digitalis or santonin is well documented elsewhere, but evidence of useage of either drug by van Gogh cannot be substantiated. It is unlikely that ageing of the human lens was an influence because of the artist's youth. Sunstroke is too restrictive to fit the multiplicity of regions and motifs. Hallucinations induced by absinthe, the popular liqueur of the period, may explain particular canvases but not the majority of 'high yellow' paintings. Van Gogh's proclivity for exaggerated colours and his embrace of yellow in particular are clear from his letters and, in contradistinction to chemical or physical insults modifying perception, artistic preference is the best working hypothesis to explain the yellow dominance in his palette.
\end{abstract}

Vincent van Gogh died by suicide in 1890 at the age of 37 years. He was a full-time artist during the last ten years of his life but received little recognition during his lifetime. A wider appreciation of his work was slowly realised during the early years of this century, and has now grown into enormous popularity. There have been numerous attempts to define van Gogh's innovations, to suggest the mechanisms of their genesis, and to identify influences upon his creativity.

It is generally thought that Vincent* had a mental illness, although consensus has not been reached on a specific diagnosis. Most commentators suggest that additional factors exacerbated his condition, even if it were hereditary; for example, Hemphill ${ }^{1}$ reached the conclusion that van Gogh was a manicdepressive who developed confusional episodes and fits which were due to excessive consumption of a popular liqueur called absinthe. Several other working hypotheses posit medical problems having some influence on his art; analyses of neurological, nutritional, environmental, and chemical factors have all received some discussion. These elements influenced his life, and some of them probably shortened it, but did they affect his vision, his style, his palette?

Chromatopsias are usually reversible but

*van Gogh preferred the use of the first name professionally; those paintings which he signed (a fraction of the total) were simply inscribed Vincent.

From: ${ }^{1}$ Department of Biochemistry and Molecular Biology, University of Kansas Medical Center, Kansas City, Kansas, USA $66103 .{ }^{2}$ Department of Medicine, University of Missouri-Kansas City School of Medicine, Kansas City, Missouri, USA 64108.

Correspondence to: Wilfred N. Arnold, PhD, Department of Biochemistry and Molecular Biology, University of Kansas Medical Center, Kansas City, USA 66103. 
would change one's view of the world and might impress an artist for later rendition on canvas. Lee ${ }^{2}$ was the first to propose that van Gogh may have suffered from digitalis intoxication, noticed the golden and coronal symptoms and, when these side effects disappeared, purposefully continued to paint with a yellow dominance. There is no record of Vincent taking the drug. Nevertheless we thought it worthwhile to explore other chemicals which can induce xanthopsia.

The dominance of vibrant yellows and the red end of the spectrum in several paintings after 1886 was declared by the artist himself as a 'high yellow note' (letter 581). ${ }^{3}$ Was it a reflection of Vincent's new perception of his subject matter or was it artistic preference? The thrust of this review is to examine existing claims, to explore new possibilities, and to resolve the issue between perception and preference.

\section{Van Gogh's 'high yellow' paintings}

From 1886 to 1890 van Gogh produced at least 638 paintings. ${ }^{+}$We have examined 276 paintings from this period. ${ }^{4-10}$ These works were produced in Paris $(20 \%)$, Arles $(39 \%)$, St. Rémy (24\%) and Auvers-sur-Oise (17\%). In order to distinguish between realistic representation of a particular scene compared with the same under perception modification it is essential to define 'high yellow' pictures as not only being rich in yellows, but virtually lacking blues, violets and white. We emphasise that the exclusion of the blues is just as important as the dominance of the yellows in arguments invoking xanthopsia. We found $10 \%$ in this category. There are other canvases within this time frame which are rich in yellows, greens, and reds but have a blue or violet swath; in this category we found $30 \%$. The warmer hues pervade many of the remainder, but they have a more general, full-

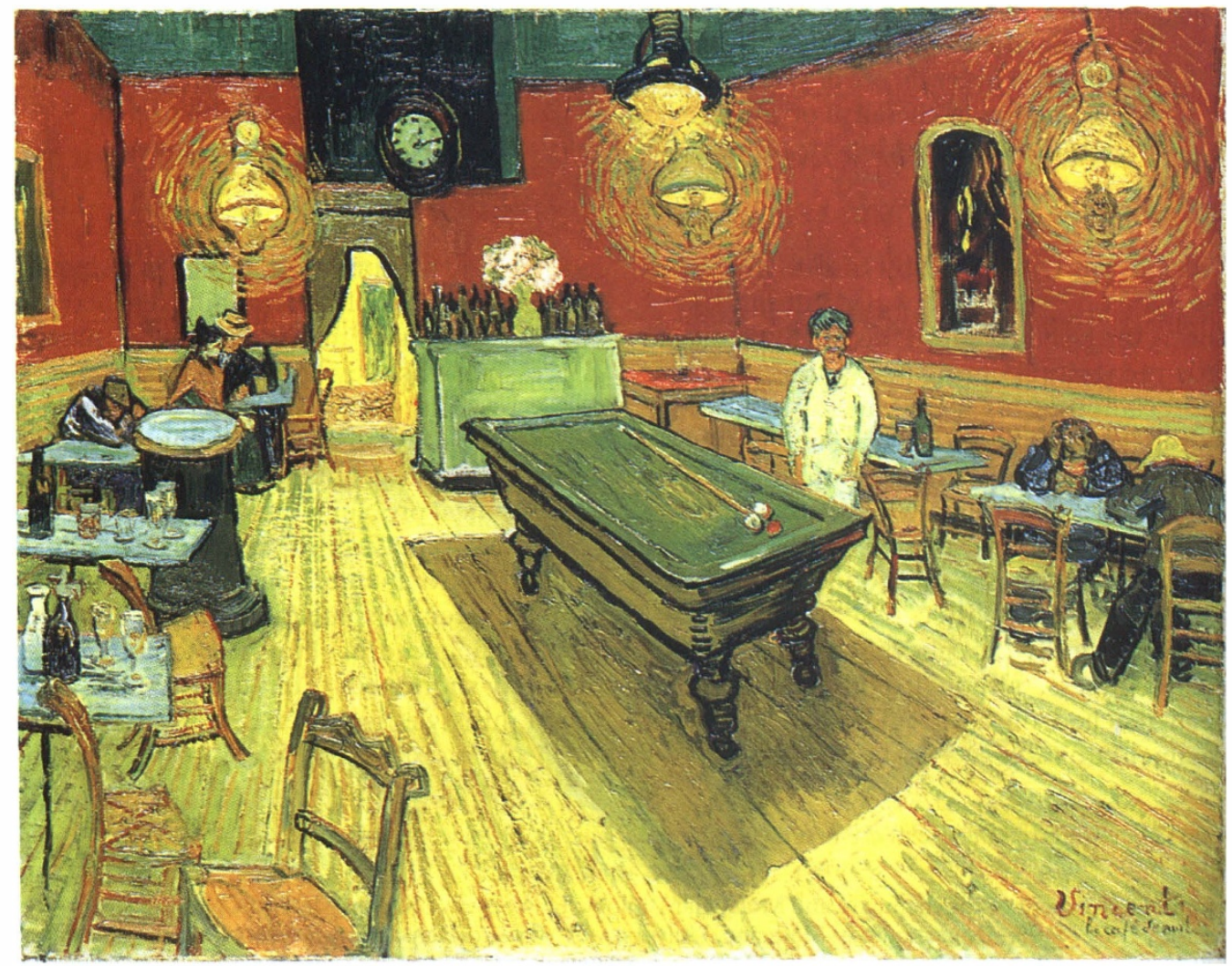

Color Plate. 'The Night Café' by Vincent van Gogh, Arles, 1888. Oil on canvas, $72.4 \times 92.1 \mathrm{~cm}$. Yale University Art Gallery, New Haven. Bequest of Stephen Carlton Clark. 
spectrum palette that includes the blues. Here we found $161(60 \%)$ of which only 13 were judged to be sombre. [Van Gogh 'touched up' many of his canvases, sometimes months later, and perhaps on occasion towards a more balanced palette, but we have not attempted to evaluate this aspect]. The Table provides examples of each of the three, operationallydefined categories.

In addition, a group of self-portraits was analysed as a separate class based upon Bonafoux's book ${ }^{11}$ of 37 canvases by van Gogh. Twenty-eight of them were created in Paris. We deem eight of these portraits to be high yellow paintings and only one, 'Self-portrait dedicated to friend Laval', 1888, was painted in the South. Thus 'high yellow' paintings were not only significant in number, but their execution was episodic, and they were produced at multiple locations. Was this a reflection of an occasional, reversible change in the artist's perception of his subject matter?

\section{Colour perception and ageing}

The perception of the full range of colours is subject to a multitude of influences. One natural example concerns ageing. The fraction of incident light energy which reaches the retina decreases with age; this is primarily due to a gradual loss in transmittance by the lens. ${ }^{12}$ The attenuation is more pronounced for the shorter wave lengths and is maximal between $450 \mathrm{~nm}$ and $470 \mathrm{~nm}$, which are centered about the colour responses of violet and blue respectively, and may be the explanation for less blue and more grey and green in the skies of older landscape painters because of yellowing of the lens. ${ }^{13}$ Pokorny et al. ${ }^{14}$ summarised the available data on healthy eyes of different ages, and with their equations we calculated that the loss in lens transmission between ages 27 and 67 is a significant $28 \%$ at $460 \mathrm{~nm}$. But for Vincent, over his artistic career (ca 2737 ), the predicted change for healthy eyes is less than 7\%, and this degree of 'yellowing' of the lens is insignificant compared with the impact that attends the unnatural condition of xanthopsia, a pathology of the colour sense which elicits yellow vision. Walsh and Hoyt ${ }^{15}$ mention at least thirteen chemicals that can cause xanthopsia; some are 20th century drugs, others include digitalis and santonin which were used in France during the period of interest.

\section{Digitalis intoxication}

Withering's book (1785) on the medical uses of foxglove (Digitalis purpurea) reported yellow vision in patients who received large and sustained doses of foxglove decoctions. ${ }^{16}$ Purkinje (1823) described his own symptoms after self-administration of digitalis. ${ }^{17}$ Lely and van Enter $^{18}$ reported a large-scale digitoxin intoxication in 1969 due to an error in tablet manufacture, and they observed serious eye conditions in $170(95 \%)$ of the patients. As well as episodes of amblyopia and diplopia, and experiences of light flashes and scintillating scotomata, patients and volunteers complained of aberrancies in

Examples of the Three Palettes Each painting is identified by origin, year, title, de la Faille (F) number, ${ }^{4}$ and present location. See text for operational definitions of the three categories.

\begin{tabular}{ll}
\hline I. 'High Yellow' & \\
Paris (1887) & 'Sunflowers' F376, Kunstmuseum Bern \\
Arles (1888) & 'The Night Café' F463, Yale University Art Gallery \\
St Rémy (1890) & 'Roses' F681, W. Averell \& Pamela C. Harriman Collection \\
Auvers (1890) & 'Trees' F817, Joseph H. Hazen Collection \\
II. 'Blue Swath' & \\
Paris (1887) & 'The Bathing Boat' F311, Mellon Collection, Virginia Museum \\
Arles (1888) & 'Wheat Field' F411, Rijksmuseum Vincent van Gogh, Amsterdam \\
St Rémy (1889) & 'The Reaper' F618, Rijksmuseum Vincent van Gogh, Amsterdam \\
Auvers (1890) & 'Sheaves of Wheat' F771, Dallas Museum of Art \\
III. 'Full Spectrum' & \\
Paris (1887) & 'Restaurant Interior' F342, Rijksmuseum Kröller-Müller, Otterlo \\
Arles (1888) & 'Café Terrace by Night' F467, Rijksmuseum Kröller Müller, Otterlo \\
St Rémy (1889) & 'Starry Night' F612, Museum of Modern Art, New York \\
Auvers (1890) & 'Crows over the Wheat Field' F779, Rijksmuseum Vincent van Gogh, \\
& Amsterdam \\
\hline
\end{tabular}


colour vision wherein all objects appeared primarily green, yellow, or white; the latter symptoms disappeared in a few days after withdrawal of the drug. ${ }^{19}$ There is no unanimity on mechanism, but Gibson et al. ${ }^{21}$ proposed that the yellow vision of digitoxin toxicity is related to a selective, reversible effect on receptors rather than the optic nerve. ${ }^{21}$

Robertson et al. ${ }^{22}$ emphasised that patients are generally reluctant to admit to distorted colour vision, thus the statistics are possibly underestimated. Nonetheless a large body of literature covering 200 years supports the fact that digitalis intoxication can induce xanthopsia. Lee ${ }^{2}$ put forward the case for Vincent van Gogh. Rentchnick ${ }^{23}$ and Lanthony ${ }^{2+}$ found some support for this working hypothesis and joined $\mathrm{Lee}^{2}$ in reminding us that digitalis was given for epilepsy, mental illness, and other medical problems in the nineteenth-century (albeit, inappropriately by modern standards). These authors ${ }^{2.23 .24}$ were intrigued by the sprigs of foxglove that Vincent incorporated into the two 'Portraits of Dr. Gachet', Auvers-sur-Oise, 1890. We are more inclined to interpret the plant as a symbol for the physician rather than as a drug for the artist. Ravin $^{25}$ noted that because Gachet was a homeopathic physician he was less likely to have administered a toxic dose of digitalis. In any event van Gogh's last attending physician, Dr. Paul Gachet, was in contact for only two months just before the artist's death. If one of his earlier doctors, e.g. Drs. Peyron (St. Rémy), Rey (Arles), or Gruby (Paris), had been similarly depicted with digitalis, then a more meaningful (but still circumstantial) case could have been made to infer prescription of the drug. There is also the possibility of self-administration by van Gogh although we find nothing about digitalis in his correspondence; he did mention taking potassium bromide at Arles (letter 574) so that he was not averse to talking about medications. Perhaps an indirect case can be made for santonin because it was recommended by Raspail, whose system of medicine was known to the artist [(letter 576), and ref. 26].

\section{Raspail}

Francois-Vincent Raspail (1794-1878), a unique, popular, and influential figure in 19th century France, had already made appreciable contributions to chemistry, biology, and particularly histochemistry when he turned his attention to the health and welfare of the general population. His system stressed hygiene, focused on common medical problems, and depended on a few chemicals such as camphor (unfortunately touted as a panacea) and a handful of crude plant extracts. He published 'Manuel Annuaire de la Santé' in pocket-book format starting in 1845, and sales averaged over a hundred copies a day in the first five years. ${ }^{27}$ It was repeated every year but two until his death, and then it was continued by his descendants till 1935 . 'How can I consider myself a doctor when all the world is going to become, without much pain, as learned as I', wrote Raspail on the title page of the Manuel, ${ }^{28}$ to the chagrin of most other physicians of the day. Raspail's contentiousness extended into politics, which landed him in jail for more than two years and exile for nine, but his publications, speeches and ministrations elevated his recognition to a household name.

Vincent was preoccupied with his own health and even wrote to his brother, as early as July 1880 , about the wisdom of self-study in medicine (letter 133), and expressed some organised scepticism about prevailing norms of health care (letter 148). Attraction to the low-cost, home-remedies of Raspail (letter 576) by someone of Vincent's demeanour is easily understood. Indeed, he lauded Raspail and incorporated an image of the Manuel into 'Still Life: Drawing Board with Onions', which was painted between January 8 and 17, 1889. During the same period Vincent wrote about his enthusiasm for camphor in overcoming insomnia (letter 570); this was surely inspired by the book, although Vincent's reckless 'very, very strong dose . . . in my pillow and mattress' can be compared with Raspail's directive of chewing about $50 \mathrm{mg}$ at night.

Van Gogh had a copy of the Manuel, considered it worthy of a legible title in his painting, and joined thousands of compatriots in consulting this book of home remedies. We do not know which edition Vincent had, but we consulted the 1863, '72 and '86 versions 
wherein we found the same entry (pp 133-4 of the 1886 edition $^{28}$ ) on semen-contra (called santonica in the 1886 U.S. Dispensatory ${ }^{29}$ ), which contained santonin as the active principle.

\section{Santonin}

This sesquiterpene lactone is found in several Artemisia species although the commercial source is primarily $A$. maritima. ${ }^{30}$ Santonin, as a crude decoction or powder and later as pure crystals, was used effectively as an anthelmintic for several centuries until displaced by drugs with less side effects. Xanthopsia due to santonin overdosage was probably encountered almost as soon as its efficacy against ascariasis was established and was documented $^{31}$ as early as 1806 . It may also be important for the present discussion to note that while bright objects are yellow, dark surfaces sometimes have a violet appearance under santonin xanthopsia. ${ }^{32,33}$ The visual symptoms may occur in the absence of all other toxic manifestations, which in extreme cases include convulsions. ${ }^{33}$

A single dose of $200 \mathrm{mg}$ santonin (about the upper limit of the therapeutic range) is sufficient to cause yellow vision in some individuals after two hours, and with $500 \mathrm{mg}$ or more the effect is noted in a half hour. ${ }^{32}$ DukeElder ${ }^{19}$ reported that doses as small as $100 \mathrm{mg}$ santonin commonly caused yellow vision. Raspail suggested up to $2 \mathrm{~g}$ daily of semencontra, the unexpanded flora heads of $A$. maritima, as often as required; this would have been equivalent to about $80 \mathrm{mg}$ santonin according to our calculation, although the concentration would have varied with the dried herb. More importantly, Raspail's direction, 'a pinch with three fingers equals one gram,' is a bit imprecise. The large variations in actual amount taken, the small difference between therapeutic and toxic doses, and individual differences in sensitivity to santonin are sufficient to account for the incidence of intoxication. ${ }^{32}$

The drug was also taken in the 19th century as a preventative medicine or in response to vague and indefinite diagnoses. More recently, documented examples involved individuals suffering dyspepsia and other gastrointestinal complaints who self-administered ${ }^{34}$ or were given by relatives, ${ }^{35}$ santonin-containing preparations. Van Gogh frequently complained of gastrointestinal problems and may have suspected worms; his penchant for excess, as exemplified with camphor, may have led to overdosage on santonin. Arnold has suggested that van Gogh's affinity for absinthe developed into a pica for terpenes, the documented examples being thujone, camphor, and pinene. ${ }^{36}$

\section{Absinthe}

Indulgence in alcohol adding to van Gogh's illness and the injurious effects of absinthe in particular have been emphasised. ${ }^{1,36,37}$ This liqueur was very popular in 19th century France; the per capita consumption was particularly high in Paris and Arles in van Gogh's time ${ }^{38}$ and there are several indications that he developed an affinity for it. $\mathrm{He}$ also painted 'Absinthe Glass and Carafe', Paris, 1887, and included a green absinthe bottle into 'Still Life: Drawing Board with Onions', Arles, 1889. Vincent said that he painted 'The Night Café' on the spot, staying up three nights in a row and sleeping during the day (letter 533). It is tempting to speculate that he consumed absinthe during the execution of this painting; he certainly had access, and the landlord was apparently pleased with the whole event. Vincent surmised that Tersteeg (an Art Gallery manager in Holland) would surely judge Vincent as having 'delirium tremens' while painting this picture (letter 534). Apart from the possibility of special cases such as this we do not imply that van Gogh painted while intoxicated. We feel that his creations occurred while lucid, but that novel experiences of relative sizes, shapes, and colours perceived under the influence of absinthe may have been recalled later and incorporated into new and daring compositions, perspectives, and palettes.

Absinthe contained high concentrations of both alcohol and essential oils from herbs; the latter contributed to flavour, fragrance, and toxicity. ${ }^{39}$ The most deleterious constituent was thujone, which can cause auditory and visual hallucinations (described as vivid and terrifying), convulsions, and eventually irreversible neurological damage. ${ }^{40,41}$ In the 1920 s and 30s, thujone- and camphor-induced con- 
vulsions were studied as models for epilepsy. ${ }^{39}$ Subsequently camphor, pentylenetetrazole (Metrazole), and hexafluorodiethyl ether (Indoklon) were used successfully as pharmacologic agents to induce convulsive seizures in certain cases of schizophrenia, i.e. chemical forerunners of electroconvulsive therapy. ${ }^{39,42}$ Therapeutic doses of Metrazole commonly evoked xanthopsia ${ }^{43}$ or varicoloured visual hallucinations ${ }^{44}$ in the preconvulsant period.

Notwithstanding chemical differences between Metrazole, camphor, thujone, and santonin, all can act as convulsants; that Metrazole and santonin cause xanthopsia is also intriguing. Amblyopia and optic neuritis were reported under absinthism, ${ }^{33}$ but chromatopsia was not encountered in our literature search. Hilbert wrote about a young, neurasthenic, male patient who suffered a three hour bout of xanthopsia after an alcoholic excess, but the liquor was not specified. ${ }^{45}$

The herbs incorporated into absinthe varied with the manufacturer but always included wormwood (Artemisia absinthium) and Roman wormwood (Artemisia pontica) ${ }^{39}$ and we wondered whether they contained santonin (cf. Artemisia maritima). The procedure used, as well as the low concentration of santonin reported for A. absinthium, excused that species; our own analyses of an alcoholic extract of $A$. pontica (i.e. simulation of the secondary process in absinthe manufacture) indicated that the amount of santonin was insignificant. ${ }^{46}$ Nonetheless, van Gogh's over indulgence in absinthe, ${ }^{36}$ and an increased susceptibility to its toxic effects due to inadequate diet, ${ }^{39}$ may have influenced his perception. According to Signac, 'Though he [Vincent] ate hardly anything, what he drank was always too much ... a after spending the whole day in the blazing sun [painting] . . . the absinthes and brandies would follow each other in quick succession. ${ }^{47} \mathrm{We}$ are also reminded of Vincent telling his brother, about his early months in Arles, 'Dr. Rey says that... I kept myself going on coffee and alcohol... it is true that to attain the high yellow note that I attained last summer, I really had to be pretty well keyed up' (letter 581). 'Now if I recover, I must begin again, and I shall not again reach the heights to which sickness partially led me' (letter 570).

\section{'Too much sun for a nordic head'}

We quote from the mid-thirties, doctoral dissertation of Beer $^{48}$ who attributed the diagnosis of sunstroke to Dr. Paul Gachet, without documentation. Our survey indicated that 'high yellow' paintings were not restricted to the south and included some indoor scenes, still lifes, and self-portraits so that sunstroke or heat exhaustion could not be the sole contributing factor.

Nevertheless Vincent remarked upon being 'dazed with the sun,' (letter 512) that 'beats down on one's head... [and] makes one crazy' (letter B 15.). He noted that sunburn was common around Arles (letter 498a), and commented upon his own sometimes reckless exposure (letter B 7). The syndrome has been recognised since biblical times. According to an 1886 Handbook, vision is sometimes affected by heatstroke; sixty cases of chromatopsia were observed in New York City about this time. ${ }^{49} \mathrm{It}$ is curious that more recent reviews ${ }^{50}$ of heatstroke do not mention chromatopsia; perhaps the syndrome is included under delirium or goes unreported because of the stigma attached to admitting to hallucinations. ${ }^{22}$

Duke-Elder ${ }^{19}$ and Carroll ${ }^{51}$. were of the opinion that the visual disturbances due to digitalis intoxication, and some other chemically invoked chromatopsias, are actually hallucinations, i.e. due to central function impairment caused by the drug. This working hypothesis has the charm of being able to embrace such disparate causes of xanthopsia as digitalis, santonin, and sunstroke but otherwise remains in conflict with hypotheses that depend more on specific chemical or physical effects on photoreceptors. ${ }^{20}$

We encountered other chemical and environmental causes of xanthopsia, ${ }^{15,33}$ but they were dismissed because they were either isolated and exotic (e.g. picric acid, chromic acid, carbon disulfide, oil of wintergreen) or seemed to be irrelevant to Vincent's lifetime (e.g. amyl nitrite, streptomycin, sulfonamides, DDT, quinacrine, thiazide diuretics). Those chemical and physical factors which we have discussed are at least reasonable can- 
didates for causing confusion or distortion in colour perception.

\section{Vincent's preference}

We turn now to 'artistic preference' and the key distinction in our operational definition is that the artist views the motif accurately but elects to depart from realistic depiction of colours on the canvas. That the artist's choice of pigments be conscious, accurate and uninfluenced by external factors is central to this argument. In 1886 van Gogh declared that, 'true drawing is modelling with colour' (letter 459a). Later , in 'La Berceuse' ('Woman Rocking the Cradle'), Arles, 1889, he strove for facial modelling by 'naturally broken tones' upon a 'complexion [of] chrome yellow' and hoped, above all, to paint a 'lullaby in colours' (letter 571a). Here, and elsewhere, the artist invokes a deeper emotional language as well as a new visual technique; the preoccupation is with colour. Furthermore, Vincent had earlier embraced 'the artist's liberty to exaggerate, to create . . . a world more beautiful, more simple, more consoling than ours'; in this artistic licence he claimed no originality but embellished a prefatory statement from Maupassant's 'Pierre et Jean' (letter 470). And elsewhere there is ample evidence from van Gogh himself to indicate that he was prepared occasionally to depart from 'exact' colour (letter 533). His colour selections for 'The Night Café' were subsequently described by Vincent as achieving an '[expression of] the terrible passions of humanity by means of red and green' (letter 533). The disparate reds, greens, orange, and yellows meant, 'an atmosphere like a devil's furnace' (letter 534). It is interesting to compare Gauguin's rendition of the same room, 'In an Arles Café', 1888, for the application of a cooler palette.

Van Gogh apparently found the Midi a perfect environment for his study of colour. Although the subjects of people and landscapes were similar in character to Holland, 'the difference [was] in the colour' (letter 488). 'How lovely yellow is! And how much better I shall [later] see the North!' (letter 522). His preference can be gauged from letters (1887-1890) wherein he mentions the yellow of his surroundings more than any other colour. Yellow also had a special symbolism for Vincent: 'The Wheatfield behind Saint Paul's Hospital with a Reaper,' 1889, a work predominantly in yellow, was described as, 'a vague figure fighting like a devil . . . the image of death ... [and] humanity might be the wheat he is reaping' (letter 604). But, most important for Vincent, 'there is nothing sad in [this] death, [because] it goes its way in broad daylight ... with a light of pure gold' (letter 604). This is reminiscent of Goethe's conviction that the colours of yellow, orange, and cinnabar (vermillion) evoke quick, lively, aspiring feelings. ${ }^{52}$ Later van Gogh hesitated over the colour rendition of this picture, but 'preferred the canvas done from nature [over a later copy] ... [because it] makes me recall the furnace of summer ... it is not so exaggerated after all' (letter 608).

\section{Conclusion}

An extensive search of the literature revealed several chemical and physical precipitants of xanthopsia. Some of these are reasonable candidates for Vincent van Gogh, but none can be supported in depth. We obviated natural ageing of the lens because of Vincent's youth and short career span. Digitalis intoxication has sufficient medical underpinning but lacks usage documentation. They physiological case for overdosage on santonin is as good or better than that for digitalis, but the evidence is still circumstantial (Raspail's book and the terpene connection). Other chemical insults are known to induce xanthopsia, but no relationship could be established with van Gogh. Sunstroke does not fit the multiplicity of motifs or locations for the yellow paintings. Only a minority of the paintings may have been directly influenced by absinthe-induced hallucinations. Irreversible brain damage from absinthism is not supported by the episodic nature of the yellow paintings. Artistic preference remains the best working hypothesis to explain the yellow dominance in his palette, a position which is upheld by his stated philosophy.

\footnotetext{
References

${ }^{1}$ Hemphill RE: The illness of Vincent van Gogh. Proc R Soc Med 1961, 54: 1083-88.

${ }^{2}$ Lee TC: van Gogh's vision: digitalis intoxication? J Am Med Assn 1981, 245: 727-9.
} 
${ }^{3}$ The complete letters of Vincent van Gogh. 2nd ed. Boston, New York Graphics Society, 1978.

${ }^{4}$ de la Faille JB: The works of Vincent van Gogh: his paintings and drawings. New York, Reynal \& Co, 1970.

${ }^{5}$ Pickvance R: van Gogh in Arles. New York. Metropolitan Museum of Art, 1984.

${ }^{6}$ Pickvance R: van Gogh in Saint Rémy and Auvers. New York. Metropolitan Museum of Art, 1986.

${ }^{7}$ Stein S: van Gogh: a retrospective. New York. Park Lane, 1986.

${ }^{8}$ Barrielle JF: The life and work of Vincent van Gogh. Secaucus, New Jersey. Chartwell Books Inc, 1984.

${ }^{9}$ Zurcher B: Vincent van Gogh: Art, life and letters. New York. Rizzoli, 1985.

${ }^{10}$ Hulsker J: The complete van Gogh: paintings, drawings, sketches. New York. Harry N. Abrams Inc. 1980.

${ }^{11}$ Bonafoux P: van Gogh self portraits. New York. Tabard Press, 1989.

${ }^{12}$ Boettner EA and Wolter JR: Transmission of the ocular media. Invest Ophthalmol Vis Sci 1962, 1: 776-83.

${ }^{13}$ Trevor-Roper PD: The influence of eye disease on pictorial art. Proc $R$ Soc Med 1959; 52: 721-44.

${ }^{14}$ Pokorny J, Smith VC, Lutze M: Ageing of the human lens. Appl Optics 1987; 26: 1437-40.

${ }^{15}$ Walsh FB and Hoyt WF: Clinical neuro-ophthalmology. 3rd ed. Baltimore. Williams \& Wilkins, 1969: vol 3, 2541-2716.

${ }^{16}$ Withering W: An account of the foxglove and some of its medical uses. Birmingham, Robinson, 1785.

${ }^{17}$ Hanzlik PJ: Jan Evangelista Purkyne (Purkinje) on disturbances of the vision by digitalis. J Am Med Assn 1925, 84: 2024-2025.

${ }^{18}$ Lely $\mathrm{AH}$ and van Enter CHJ: Large-scale digitoxin intoxication. Br Med J 1970, 3: 737-40.

${ }^{19}$ Duke-Elder S: System of ophthalmology. St. Louis. Mosby, 1972: vol. XIV.

${ }^{20}$ Gibson HC, Smith DM, Alpern M: $\mathrm{P}_{5}$ specificity in digitoxin toxicity. Arch Ophthalmol 1965, 74: 154-58.

${ }^{21}$ Unger L: Chromatopie nach digitalis. Ophthalmologica 1958, 136: 326-32.

${ }^{22}$ Robertson DM, Hollenhorst RW, Callahan JA: Ocular manifestations of digitalis toxicity. Arch Ophthalmol 1966, 76: 640-5.

${ }^{23}$ Rentchnick P: Pathographie, van Gogh. Medecine et Hygiene 1987, 45: 1753-61.

${ }^{24}$ Lanthony P: La xanthopsie de van Gogh. Medecine et Hygiene 1988, 46: 2466-72.

${ }^{25}$ Ravin JG: van Gogh's Illness. Ohio State Med J 1981, 77: 699-702.

${ }^{26}$ Nordenfalk C: van Gogh and literature. J Warburg Cortauld Inst 1947, 10: 132-47.

${ }^{27}$ Weiner D: Raspail, scientist and reformer. New York and London. Columbia University Press, 1968.

${ }^{28}$ Raspail FV: Manuel annuaire de la santé pour 1886. Paris. Chez l'Editeur, 1886.

${ }^{29}$ Wood GB and Bache F: The dispensatory of the
United States of America. 15th ed. Philadelphia. JB Lippincott \& Co. 1886: 1270.

${ }^{30}$ Simonsen JL: The terpenes. Cambridge. Cambridge University Press, 1949: vol 2.

${ }^{31}$ Wood CA: The American encyclopedia and dictionary of ophthalmology. Chicago. Cleveland Press, 1919: vol 17, 12861.

${ }^{32}$ Marshall W: A study of santonin xanthopsia. J Pharmacol Exp Ther 1927, 30: 361-88.

${ }^{33}$ Grant WM: Toxicology of the eye. 2 nd ed. Springfield, Illinois. Charles C. Thomas, 1974.

${ }^{34}$ Cookson HA and Stock CJH: Santonin poisoning, fatal case. Lancet 1940. 2: 1940, 745.

${ }^{35}$ Oldham RR, Wang YM, van Eys J, Carter JP: Hemolytic crisis in a patient treated with santonin: possible santonin poisoning. South Med J 1971, 64: 480-2.

${ }^{36}$ Arnold WN: Vincent van Gogh and the thujone connection. J Am Med Assn 1988, 260: 3042-4.

${ }^{37}$ Monroe RR: The episodic psychoses of Vincent van Gogh. J Nerv Ment Dis 1978, 166: 480-8.

${ }^{38}$ Schmidt H: L'Absinthe l'alienation mentale et la criminalite. Annals d'Hygiene Publique et Medecine Legale 1915, 23 (4 serie): 121-33.

${ }^{39}$ Arnold WN: Absinthe. Sci Am 1989, 260: 112-7.

${ }^{40}$ Magnan V: On the comparative action of alcohol and absinthe. Lancet 1874, 2: 410-12.

${ }^{41}$ Sollmann T: A manual of pharmacology and its applications to therapeutics toxicology. 7th ed. Philadelphia. WB Saunders Co, 1948.

${ }^{42}$ Kalinowsky LB, Hippius H, Klein HE: Biological treatments in psychiatry. New York. Grune \& Stratton, 1982: chapter 3, 217-221.

${ }^{43}$ Dean SR: Studies in convulsant therapy. IV. The effects of metrazol (pentamethylenetetrazol) on the eye. Arch Ophthalmol 1940, 24: 316-25.

${ }^{44}$ Friedman E: Irritative therapy of schizophrenia. $N Y$ State J Med 1937, 37: 1813-21.

${ }^{45}$ Hilbert R: Zur kenntnis der genuinen chromatopsien. Klinische Monatsblatter fur Augenheilkunde 1913, 51: 494-7.

${ }^{46}$ Arnold WN, Dalton TP, Loftus LS, Conan PA: A search for santonin in Artemisia pontica, the other wormwood of old absinthe. J Chem Ed 1991, 68: 27-28.

${ }^{47}$ Item A16. In The complete letters of Vincent van Gogh. 2nd ed. Boston: New York Graphics Society 1978, vol 3. 605.

${ }^{48}$ Beer J: Essai sur les rapports de l'art et de la maladie de Vincent van Gogh. These, Doctorat en Medecine, L'Universite de Strasbourg, 1935.

49 Satterthwaite TE: Heat-stroke. In Buck AH, ed. A reference handbook of the medical sciences. New York: William Wood \& Co, 1886: vol III, 600.

${ }^{50}$ Stanford JF: Heatstroke, a review of clinical manifestations and management. Mo Med 1986, 83: 371-4.

${ }^{51}$ Carroll FD: Visual symptoms caused by digitalis. Am J Ophthalmol 1945, 28: 373-6.

${ }^{52}$ Goethe JW: (Eastlake CL, Translator) The theory of colours. Cambridge. MIT Press, 1970. 